\title{
Ante el volcán. La Iglesia en la Cuba prerrevolucionaria.
}

\section{John M. Kirk \\ Dalhousie University, Canadá.}

En los últimos affos ha aumentado considerable y masivamente el interés por las iglesias y sus relaciones con las luchas de liberación política. En Filipinas, el cardenal Sin llegó a convertirse en la voz más crítica del régimen de Marcos, mientras en Polonia suele presentarse a la Iglesia como la gran opositora al régimen de Jaruzelski. Sin embargo, las iglesias que más interés han suscitado a este respecto son las iglesias de América Latina, en Chile, Paraguay, Brasil y. sobre todo, en Centroamérica.

El triunfo popular sandinista es lo que explica, hasta cierto punto, este nuevo interés por la actuación de las iglesias; pero también ha ayudado a que el interés sea cada vez mayor, la represión de los católicos en Guatemala, por ejemplo, o el surgimiento de la Iglesia popular o de los pobres en El Salvador y la figura inspiradora de Monseñor Oscar Romero. Pareciera que las agencias de prensa mundiales han "descubierto" el fenómeno revolución-religión y lo tratan de explotar hasta la úluma gola. De ahí su interés por convertir en noticia el papel del sacerdote en la guerrilla o la confrontación entre el Vaticano y la llamada "Iglesia popular" o la confrontación entre aquél y los que apoyan la teología de la liberación, y muchos otros fenómenos eclesiales que har convertido a la Iglesia en "noticia."

Esta novedad publicitaria tiene, sin embargo, serios vacíos. Tiende a concentrarse exclusivamente en los hechos o en los incidentes de los últimos ocho años, como el martirio de Mons. Romero, el de las religiosas estadounidenses, el de tantos sacerdotes comprometidos, como Rutilio Grande, o en la fracasada visila de Juan Pablo II a Centroamérica; o en las tensiones entre la jerarquía y las comunidades de base. Todo ello, aunque de por sí muy interesante $\mathrm{c}$ importante, no es más que un aspecto de la historia multifacética de la Iglesia en "Nucstra América," por usar la icrminología martiana. 
Este ensayo quiere llenar uno de esos vacios y concentrase en un momento coyuntural de esa historia tan rica; más específicamente, en la situación de la Iglesia católica cubana en la época anterior a otra de las grandes revoluciones de este siglo: la revolución cubana. Queremos examinar el papel que jugaba la Iglesia en la Cuba de los anos cincuenta, su naturaleza, su composición y sus metas. Nuestra hipótesis es que, conociendo mejor la realidad de la Iglesia en ese período tan decisivo de la historia nacional cubana, mejor podremos comprender los conflictos, tan amargos, entre la Iglesia y la revolución a partir de 1960.

\section{Un bosquejo histórico: la Iglesia cubana en la primera mitad del Siglo XX}

Antes de comenzar el ańlisis de la década de los cincuenta, creemos que vale la pena echar un ligero vistazo a lo que había sucedido en la Iglesia cubana desde la lucha de la independencia y la mal lamada guerra hispano-norteamericana. En efecto, muchos de los rasgos predominantes en la época posterior tienen su origen en la situación eclesiástica de este perfodo, tan importante en la definición de la nacionalidad cubana. Tomado en su conjunto, esto nos ayudará a comprender mejor la situación y actuación de la Iglesia en los afios cincuenta.

Al comenzar la última fase de la guerra de la independencia de las fuerzas mambisas, en 1985, la Iglesia católica se encontraba en una situación de notable deterioro: materialmente pobre y hasta cierto punto olvidada por la "madre patria", la cual durante la época colonial habla visto a Cuba como el lugar indicado para montar una campafa militar contra las otra colonias más ricas de América Latina. A lo largo de una historia de grandes conflictos entre autoridades militares y eclesiásticas en la isla, la Iglesia defendió tercamente su limitada influencia frente a cualquier "amenaza," verdadera o imaginaria, que creía enfrentar. Por otra parte, la calidad de los religiosos era tradicionalmente muy baja; y entre las varias órdenes religiosas habian surgido rivalidades que permanecieron profundamente arraigadas.

Con la excepción de los "años dorados," 1750-1850, cuando sí florecieron las vocaciones en Cuba (recordemos que en 1768 fue nombrado obispo de Santiago Hechavarría y Elguezúa, primer prelado cubano en casi 250 antos de colonización, ${ }^{1}$ y que en ese época el Colegio Seminario San Carlos y San Ambrosio, inaugurado en 1774, en el que trabajaban los ilustres profesores - y fervientes nacionalistas - José Agustín Caballero, Félix Varela y Morales y José de la Luz y Caballero, se convirtió en símbolo vivo de las aspiraciones patrióticas), la Iglesia continuó ejerciendo su papel de protectora del status quo. Por eso, con muy pocas excepciones, la Iglesia mantuvo una actitud insensible hacia las pésimas condiciones de vida de los esclavos africanos, ${ }^{2}$ observando así lo que la Reflexion eclesial cubana ha llamado "un silencio cómplice frente a muchas de las injusticias coloniales." 3 En efecto, varios grupos eclesiáslicos eran, por ejemplo, dueños de centrales azucareras y dependian del trabajo de los esclavos.

También es necesario recordar que las reformas liberales en España, 1833- 
1840, tuvieron su impacto sobre la Iglesia cubana: se le quitaron muchas propiedades, los dominicos fueron expulsados de la universidad y se produjo un éxodo masivo de clérigos. Más tarde, a las autoridades eclesiásticas se les ofreció una compensación por estas medidas, pero exigiendo de ellas una actitud respetuosa hacia el gobiemo de Madrid. Con notables excepciones (como la de Antonio María Claret, arzobispo de Santiago de Cuba de 1851 a 1856, quien predicaba un mensaje más crítico hacia el poder español y pedía mayor justicia e igualdad, y por eso tuvo que regresar a Espafta tras 15 atentados contra su vida), 4 la Iglesia llegó a la conclusión de que su deber consista en salvar el alma de su grey y olvidarse de su cuerpo material. Y, dadas las ambiciones de las autoridades por el poder y después de haber pasado por lan malas situaciones, éstas aprendieron bien la lección.

Cuando estallo la lucha de la independencia, primero entre 1868 y 1878, y luego en la guerra de 1895-1898, la jerarquía católica trató visiblemente de evilar cualquier problema político con las autoridades militares. Conviene destacar importantes excepciones, como el caso de Pedro Nolasco Alberre, sacerdote de 82 afios que fue deportado, o el de Francisco Esquembre, fusilado por supuesta traición. Pero en general la Iglesia decidió cuidar bien de sus propios intereses, llegando al extremo de cantar un Te Deum al anunciarse la muerte de los héroes cubanos José Martl y Antonio Maceo, de convertir templos en cuarteles para las tropas espafiolas y de hacer colectas especiales para ayudar a las autoridades españolas. En general, la jerarquía había sido cooplada y la vida religiosa había caído en un vacío esteril.

Es notable el saldo desfavorable, el cual podemos resumir con los siguientes datos: ignorancia en materia religiosa, indeferentismo religioso, escasez de parroquias fuera de la ciudad y destrucción de templos durante las guerras, escasez de clero cubano. Y lo más negativo: la Iglesia (manipulada) fue arrastrada a alejarse de los intereses y necesidades de su pueblo, sobre todo por la actitud de obispos y sacerdotes espafioles muy apegados al antiguo estado de cosas en la isla ${ }^{5}$

Desafortunatamente para ella, la Iglesia consolido su posición, pero al precio de alinearse con un poder que, sencillamente, poco tenía ya que ver con la escena política contemporánea. Como resultado de haber apoyado a la corona, al ocurrir la derrota espantola, la credibilidad de la Iglesia desapareció en la sociedad cubana Además, tras la intervención estadounidense regresó a Espafta gran cantidad de sacerdotes espantoles.

Los aflos de la intervención estadounidense (1899-1902) uvieron como resultado una clara disminución de la autoridad eclesiástica: se eliminó, por ejemplo, el monopolio de la Iglesia sobre los matrimonios; se estipulo que se mantuvieran separados Iglesia y Estado y que no se otorgaran fondos para el mantenimiento de la Iglesia; se otorg6 a las aubridades civiles el derecho de conceder el divorcio; se abrieron cementerios civiles y se establecieron escuelas 
laicas. Poco a poco la Iglesia se fue dando cuenta de que, para volver a ganar respetabilidad, tenía que cambiar sus ideas y su estilo; es decir, tenía que modernizarse.

Durante las tres décadas siguientes la Iglesia trató, con bastante éxito, de mejorar su situación en Cuba. La promoción de sacerdotes nativos - caso poco frecuente antes- se convirtió en un hecho más habitual. También los colegios catolicos - habia 55 en 1914 - ayudaron mucho a crear estrechos lazos de apoyo entre la Iglesia y la burguesía criolla (ahora con gran influencia, después de la derrota espaniola). Finalmente las numerosas asociaciones socio-religiosas, que aun teniendo una vocación conternplativa se dedicaban también a ayudar a los pobres - aunque de forma netamente paternalista - lograron crear una nueva base de participación social para la Iglesia

En resumen, hacia los afios treinta, la Iglesia llegó a tener una respetabilidad que no había alcanzado durante muchas décadas de evangelización. A través de asociaciones como los Caballeros Calólicos, fundados en 1925, las numerosas ramas de la Acción Católica y la Agrupación Católica Universitaria (1931), y de una asombrosa red de revistas (como, por ejemplo, San Antonio, Belén, La Anunciata, El Mensajero, Esto vir, La Salle, Don Bosco, Rosal Dominico, Aromas del Carmelo) y de crónicas religiosas en periódicos como el Diario de la Marina, El mundo y El Pals, la Iglesia llegó a conseguir un alto grado de aceptación social, sobre wodo en los sectores urbanos de la burguesia.

Faltaba, sin embargo, una seria preocupación por la problemática social de Cuba, en parte porque el resurgir eclesístico se debia a una nueva ola de inmigaración espaftola, interesada principalmente en buscar su fortuna y en olvidar la política. De ahí que la Iglesia apareciese apoyando fuertemente todo lo que fuese "caridad", pero, en general, pasando por alto la justicia social. Tampoco se enconurarán críticas exlesiásticas serias a la intervención estadounidense de 1906-1909, $1912,1917-1920$, a la compción y a los constantes fraudes electorales o a la brutal dictadura de Machado.

Todo esto explica cómo, a un nivel superficial, la situación de la Iglesia quedó aparentemente consolidada. Én efecto, los líderes católicos, ampliamente aceptados, fortalecieron su posición social a través de la iglesias y de las numerosas asociaciones que resurgían en estas décadas. Pero, por otra partre, la Iglesia ofrecía la imagen de ignorar los serios problemas de su alrededor; y, una vez más, se limitaba a alender los intereses de una minoría poderosa, sin hacer caso de las grandes mayorías, sobre todo de los campesinos y de los negros. ${ }^{6} \mathrm{La}$ historia amenazaba, otra vez, con repetirse. Mientras tanto, muy satisfechas de su posición social, tan respetada, las autoridades eclesiásticas prelírieron no atender a los graves problemas nacionales.

Durante las décadas de los cuarenta y los cincuenta estas tendencias se agudizaron. La Iglesia se afianzó y fue cada vez más respetada, pero se negó a comprometerse con "lo terreno", dejando de lado los aspectos políticos. Excepción 
muy notable fue el arzobispo de Santiago de Cuba, Enrique Pérez Serantes, prelado muy consciente del sufrimiento de los campesinos. Pero para la Iglesia en general, éste era el momento de amonizar, de buscar relaciones mutuamente provechosas con los presidentes Grau San Martín, Prio y Batista. En el caso del dictador Batista, tras el golpe de Estado de 1952, hubo una relación especialmente respetuosa, resultado, según muchos, de la generosidad manifiesta de la segunda mujer de Batista.

De esta forma, poco antes de la revolución encabezada por Fidel Castro, la influencia política de la Iglesia iba en aumento, tras tres décadas de desarrollo eclesial y socio-económico. Después de haber estado marginada durante buena parte de su historia, la Iglesia vio cómo las úlumas tres décadas le deparaban un cambio muy dramático, lo que convenció a muchos de la necesidad de consolidar su posición social y de alejarse de cualquier critica al stalus quo. Esta postura ayudo, de momento, a proteger sus propios intereses, pero traeria después muchas dificultades a la Iglesia, sobre todo a partir del segundo afio del proceso revolucionario, cuando la polarización socio-política se hizo cada vez más aguda.

\section{La Iglesia y la lucha contra Batista}

El asalto al Cuartel Moncada en Santiago de Cuba, el 26 de julio de 1953, por Fidel Castro y sus compañeros, y las brutalidades cometidas después por las fuerzas militares del cuartel, ayudaron a despertar a la Iglesia, desafiándola a que condenase tales acciones. Pero, incluso entonces, la jerarquía en general se resislió a responder a tal desafío otra vez con la excepción notable del arzobispo Pérez Serantes, quien se dirigió a las autoridades mitares, pidiendo clemencia para los rebeldes y pidiendo, incluso, garantías para que los capturados no fueran torturados o asesinados. Su activa participación, como bien se sabe, le salvó la vida a Fidel Castro, cuyo padre -otro gallego- era amigo íntimo del arzobispo.

Aunque existen diferentes opiniones sobre la contribución de la Iglesia a la caída de Batista, lo que sí se puede afurmar, respecto a la Iglesia cubana de esa época, es que no había ninguna política oficial sobre el "caso cubano": los seis obispos, trece organizaciones laicas, numerosas ordenes, colegios, instituciones sociales, publicaciones y el nuncio del Vaticano, Mons. Luis Centoz, Lodos tenían opiniones totalmente diferentes en cuanto al papel y las obligaciones que la Iglesia debía desempeñar.

En términos generales, existían, al parecer, tres grupos de católicos en esa época. Aunque constituia una muy clara minoria, había un grupo muy vigoroso de laicos, apoyado por Pérez Serantes y, hasta cierto punto, por los obispos Evelio Díaz (La Habana) y Alberto Martín (Matanzas). Eran grupos como la Juventud Católica, la organización de los Jóvenes Obreros Católicos y la mayoría de los sacerdotes seculares cubanos. Eran bien conscientes de la brutalidad batisliana (hay que recordar que varios - incluso el Cardenal Manuel Arteaga - fueron víctimas de la violencia oficial) y de la problemálica del país, pero no poseían 
ninguna plataforma unificada ni ningún enfoque común para tratar estos problemas.

Otro grupo, con una visión política totalmente distinta, se movía en tomo a los obispos Carlos Riu Angles (español, obispo de Camagüey), y Martínez Dalmau, de Cienfuegos. Este estuvo an comprometido con la dictadura de Batista, que poco después de la victoria popular, tuvo que salir de Cuba, en enero de 1959. Este grupo tenía el apoyo de muchos de los sacerdotes espafioles, así como de los líderes de la inhuyente Agrupación Católica Universitaria y de la administración de la Universidad Villanueva. A esta heterogénca "coalición" pertenecían también los hacendados y ganaderos - además de la burgucsía urbanaquienes, a pesar de los excesos de Batista, preferían la situación existente a una revolución que pudiera reducir sus ganancias.

En medio de estas posiciones extremas se encontraba la mayoría católica, la cual o se resisúa a mezclar la política con la religión, o se mantenía indiferente ante la situación nacional. Su portavoz era el cardenal Arteaga - el primer cardenal cubano de la historia-, quien cn vano trataba de buscar una solución negociada para los grandes problemas socio-políticos, intentando un "diálogo" y una "reconciliación" imposibles.

De estas tres tendencias convienen destacar el papel desempeñado por los católicos del primer grupo, ya que a la luz de la historia de las relaciones resultantes, bastante difíciles, entre Iglesia y Estado, se ha tendido a olvidar la importancia de su contribución. Aunque estos critianos sólo eran "una minoría dentro de una minoria," su participación en la insurreción, a varios niveles, fue clave. El símbolo mejor conocido de dicha participación calólica fue el $P$. Guillermo Sardiñas, quien, aparentemente con la aprobación de la jerarquía, dejo su parroquia en la Isla de Pinos - ahora Isla de la Juventud- para ir a la Sierra Maestra como capellán del ejército rcbelde. Por el papel tan activo que jugó, se le confirió el grado de comandante; y, después de la derrota de Batista, siempre llevó una solana verde olivo, con su estrella de comandante de las Fuerzas Amadas Revolucionarias. Otros sacerdotes también sirvieron como capellanes del ejército rebelde, por ejemplo, los padres Maximino Bez, C.M., Ribas, Cánepa, y Lucas Iruretagoyena, O.F.M.; mientras otros, como los padres Francisco Beristáin y Jorge Vez Chabebe, Moisés, y Madrigal - tesorero del 26 de julio en la Habana hasta que tuvo que exiliarse en 1958-, también ofrecieron una valiosa contribución.7

Desde la mucrte de José Antonio Echeverría, dirigente estudiantil católico, en 1957, el laicado progresista había aumentado su oposición a la dictadura. Conviene aquí destacar la particpación de muchos dirigentes de la JOC en la huelga de abril de 1958. Es necesario recordar, sin embargo, dos aspectos importantes: primero, que estas personas participaron en la lucha como individuos calólicos que querían derrotar a Batista, y no como portavoces oficiales de la Iglesia; $y$, segundo, que sólo constituían una pequeñisima minoría dentro del catolicismo 
cubano, y a veces fueron tratados con hostilidad por sus correligionarios, precisamente por su actitud compromelida.

También vale la pena recordar la posición de la jerarquía catolica, sobre todo en 1958, cuando arreció de nuevo la represión de las fuerzas batistianas. El cardenal Arteaga, a pesar de haber sido alacado él mismo físicamente por un alto oficial de la policía, seguía participando — al lado de Batista - en las ceremonias oliciales, por ejemplo, en las inauguraciones de los edificios públicos. En febrero de 1958, frustrado por la fala de iniciativa de sus colegas, el arzobispo Pérez Serantes convocó a una reunión para analizar la crisis política y para decidir la posición de la jerarquía. Apoyado por los obispos Marín Villaverde y Evelio Díaz, exigió una declaración sobre la dictadura menos ambigua que la que querian promover sus colegas; pero la oposición, Martín Dalmau, de Cienfuegos,y Riu Angles, de Camaguley, la rechazó. El resultado fue una carta pastoral, publicada el 25 de febrero, que mantenía la postura "apolítica" de la mayoria. ${ }^{8}$ Por su parte, Pérez Serantes reaccionó de forma indignada ante un documento tan suave: "yo no planteé mi propuesta en esos têrminos confusos y ambiguos, ni mencioné ningún 'gabinete de unidad' nacional, como ahora se pretende hacer. Yo pedí un cambio de gobiemo, lo que incluye la salida de Batista."9

Esta falta de unidad entre los dirigentes eclesiásticos fue un rasgo úpico del papel político de la Iglesia durante el año anterior a la victoria de Fidel Castro. La jerarquía, al mantener posturas tan claramente contradictorias sobre la responsabilidad de los católicos ante los continuos abusos de Batista - hasta cierto punto era el resultado de su deseo de proteger sus propios intereses-, perdió la oportunidad de un nuevo acercamiento entre los obispos y el pueblo, sobre todo porque muchos laicos y sacerdotes seculares, al ver la naturaleza del conflicto, ya habían asumido plenarnente sus compromisos morales. Para muchos catolicos resultaba inaceptable que, ante la represión y el asesinato repetidos - hay que recordar que murieron 20.000 cubanos en la lucha contra Batista- la jerarquía -con la excepción notable de Pérez Serantes- no emitiera ninguna declaración firme al respecto. Finalmente, en diciembre de 1958 le toc6 al P. Belarmino García decir en público lo que muchos católicos progresistas pensaban sobre la postura de la jerarquía:

La jerarquía eclesiástica [...] ha dejado indefensa a la grey católica, llegando incluso a insinuar una acusación de indisciplina y rebeldía por la actitud de sus mejores sacerdotes y lieles ante el peligro gravísimo de la nación. Los altos dignatarios eclesiásticos han profesado o simulado públicamente una inconcebible indiferencia ante los hechos nefastos que los cuerpos de represión, alentados y premiados por el supremo poder del gobernante de facto, han hecho exhibición alardosa de atropellos y crueldades que ultrajan la dignidad humana y ofenden sacrilegamente al espíritu cristiano en lo más esencial de la moral. ${ }^{10}$

Si bien es cierto que, dados los acontecimientos históricos de 1959 a 1961, es 
improbable que la Iglesia hubicra jugado un papel de gran imporancia en la Cuba revolucionaria, tambićn es cierto que una Iglesia más unida y más progresista hubiera conferido a la Jerarquía un grado de credibilidad que, debido a su indecisión, ya no poseía. 11

\section{La Iglesia en 1958: un perfil socio-económico}

Aunque sea interesante destacar la visión y actitud de liguras como el $P$. Sardiffas o el cardenal Areaga, conviene recordar que ellos no representaban a la Iglesia per se, sino más bien, eran ejemplos de una minoría que, de una forma u otra, iba forjando un camino posible para los fieles. Por eso hay que preguntarse cómo era esa masa nebulosa que puede llamarse "la Iglesia" ¿Cúales eran las diferencias sociales o étnicas existentes entre sus diversos rangos? ¿Cuán homogéneo era el cuerpo de los 700 sacerdoles y 2.000 religiosas? ¿Qué diferencias económicas existían entre el sector urbano y el campo? En lin, ¿cómo se puede definir -si eso es posible- el papel de la Iglesia en la Cuba de 1958?

Si nos fijamos, en primer lugar, en los agentes cualificados de pastoral, sacerdotes, religiosas y religiosos, es muy obvio que existía un "prototipo," hecho demostrado claramente por el documento del episcopado cubano publicado en marzo de 1955. En primer lugar, la gran mayoría de los sacerdotes y religiosas eran extranjeros, españoles sobre todo. Solamente 95 de los 200 sacerdotes diocesanos, 30 de los 461 religiosos sacerdoles, 75 de los 329 religiosos no sacerdotes, 441 de las 1,549 religiosas y 115 de las 323 Hijas de la Caridad eran de origen cubano. En otras palabras, debido, en gran parte, a la falta de vocaciones nativas, la abrumadora mayoría de los sacerdotes, religiosos y religiosas eran extranjeros, y, específicamente, españoles. La presencia de tantos españoles como ocurrió en el siglo pasado- causaba naturalmente bastantc fricción, sobre todo entre los clérigos con sentido nacionalista. Adcmás, conviene recordar que casi lodos ellos habian sido formados en la España fascista del franquismo con un rechazo visceral contra cualquier tipo de filosofía izquierdizante - factor importante a tener en cuenta en la confrontación entre la Iglesia y el Estado a partir de 1960, la cual llegó a un clímax con la presencia de varios sacerdotes españoles entre los invasores de Playa Girón en abril de 1961.12

También es interesante notar el tipo de tareas a las cuales dedicaban la mayor parte de su tiempo estos sacerdotes y estas religiosas. En el mismo informe del espiscopado cubano de 1955, resulta sorprendente constatar que la tercera parte de los religiosos sacerdotes se dedicaban a la enseñanaza ( $153 \mathrm{de} \mathrm{461).} \mathrm{En} \mathrm{el} \mathrm{caso} \mathrm{de}$ los "religiosos no sacerdotes" esta cifra alcanzó el 90 por ciento (299 de los 329 eran maestros), mientras que 1.209 (de 1.872) religiosas también estaban dedicadas a la enseflanza. Nada habría que censurar en este interés por la enseñanza, si no fuera por las preguntas ¿educación para quiénes? ¿De qué tipo? Un número reducido se dedicaba a obras sociales (por ejemplo, 30 de los 329 "religiosos no sacerdotes" se ocupaban del Sanatorio y de la Clínica Infantil), aunque el porcentaje se elevaba notablemente en la religiosas,casi la mitad de ellas -136 de unas 323 - trabajaba en "diversas obras de beneficencias y apostolado." De esta forma 
podemos ver cuáles eran las prioridades de la Iglesia pocos affos antes de la revolución cubana.

Aunque había interés real en varios seciores de la Iglesia por ayudar a los menos favorecidos -véase la úlima página del informe del episcopado cubano-, 13 es evidente que se ponia mayor enfasis en la ensethanza en los colegios, en su gran mayoría de pago. Con pocas inversiones, con pocas propiedades en el campo y teniendo en cuenta la separación de la Iglesia y el Estado desde la intervención estadounidense, queda claro que la fuente principal de los ingresos eclesísticos tenían que ser los colegios de pago. Dichos colegios, además, moldeaban la fe del estudiantado - cuya gran mayoría pertenecía a la burguesía - no sólo protegiendo la postura social de la Iglesia, sino también promoviendo vocaciones religiosas.

Los autores de la citada Reflexión eclesial cubana indican que varios de los colegios eran gratuilos, mientras que otros olorgaban becas a los estudiantes más necesitados, lo cual es cierto. ${ }^{14}$ Sin embargo, hay que tener en cuenta que los 212 colegios católicos, con un estudiantado de unos 61,960 alumnos (además de la Universidad de Santo Tomás de Villanueva con otros 1,000 estudiantes), la gran mayoría eran de pago. Por eso tiene razón el católico Manuel Fernández -ahora exiliado en Espafia - al alumar que "en Cuba predominaba una educación religiosa clasista."15

La nauraleza elitista de esta educación se aprecia mejor al conocer, por ejemplo, las estadisticas con respecto al analfabetismo: al nivel nacional era del 23.6 por ciento, siendo mucho más alta, por supuesto, en las zonas nurales. Muchos se preguntaban con frecuencia si la Iglesia no serfa más efectiva concentrando sus esfuerzos en las regiones más necesitadas. Para los campesinos, desgraciadamente, la influencia religiosa en cualquier actividad de relevancia social era mínima. Incluso, a pesar de las opiniones de Carlos Manuel de Céspedes, secretario general de la conferencia espiscopal, las campatas misionales fueron en general muy limitadas. 16

En resumen, la Iglesia se despreocupó deliberadamente de las zonas nurales, y decidió concentrar sus esfuerzos en el sector urbano, donde dedicó su atención, principalmente, a la burguesía. Al fin y al cabo, este era el sector que más apreciaba y respetaba; y, además, alli encontraba los fondos necesarios para su desarrollo. Mientras tanto, el campesino vivia en condiciones muy diffciles y con poca atención de la Iglesia. Poco a poco se fue alejando de ella.

Para ilustrar la situación de la Iglesia en el campo, basta con revisar dos encuestas de reconocida seriedad, y ampliamente divulgadas, que realizó la Agrupación Católica Universitaria en 1954 y 1957 respectivamente. De acuerdo a estas encuestas, por ejemplo, el 72.5 por ciento de los encuestados se declaraban católicos, pero en el campo el porcentaje bajaba al 52 por ciento, mientras que el 41 por ciento de los campesinos se declaraban indiferentes a cualquier afiliación religiosa. ${ }^{17}$ Una clara mayorla de los encuestados créla en la existencia de Dios (el 96.5 por ciento más o menos), ${ }^{18}$ pero sólo un porcentaje baj(simo practicabe 
la religión. En el campo, por ejemplo, el 91 por ciento de todos los niflos reciblan el bautismo, pero sólo el 50 por ciento hizo su primera comunión, y no llegaban al 16 por ciento los matrimonios celebrados en la Iglesia 19

Algunos investigadores, por el afán de mostrar al pueblo cubano de esa epoca como una nación católica, han pasado por alto los resultados de estas encuestas que no encajan en sus presupuestos. Así, por ejemplo, la sección de la encuesta sobre la asistencia a misa muestra claramente una aceptación muy pobre de esta práctica religiosa.

Son también significativas las respuestas de los campesinos a la pregunta

Asistencia a misa del jefe de familia de trabajadores agricolas (1956)

\begin{tabular}{|cc|}
\hline $\begin{array}{c}\text { Número de veces } \\
\text { al año }\end{array}$ & Individuo (\%) \\
\hline 0 & 93.47 \\
1 & 2.64 \\
2 & 1.83 \\
3 & 1.32 \\
4 & 0.7420 \\
\hline
\end{tabular}

sobre su relación con el párroco. Un 7.81 por ciento loconsideraba "anigo personal" o "amigo," un 1.94 por ciento "no lo trataba" y un 36.74 par ciento "lo conoce de vista." Pero lo sorprendente es que el 53.51 por ciento declarb no haberlo visto nunco (enfasis mio). 21 Entre los campesinos catolicos, aunque unos, el 12.26 por ciento, to veían como "amigo personal, " el 27.31 por ciento "no lo ha visto nunca."22 Esto muestra claramente que la presencia católica entre los sectores marginados dejaba mucho que desear, y que los campesinos que se confesaban católicos tenían forzosamente que practicar una religión bastante superficial. ${ }^{23}$ No sorprende entonces que, ante la pregunta, "Lque institución cree el trabajador agrícola que puede mejorar su situación," solamente el 3.43 por ciento prefirió a la Iglesia, por debajo del 4.30 por ciento que optaba por la masonería 24

En las ciudades, en cambio, aunque existran grandes diferencias entre barrios ricos y pobres, había por lo menos una identidad católica. Las figuras eclesiásticas se hacian visibles en muchos actos oficiales; a la Iglesia se le prestaba bastante atención en la prensa, además de aparecer en algunos programas de televisión y radio; los colegios calólicos tenian prestigio; habla peregrinaciones masivas, como la de San Lázaro, y otra manifestaciones de religiosidad popular, y las iglesias, en general, estaban bien concurridas. En una palabra, la realided en la ciudad era completamente diferente a lo que ocuparia en el campo. 
La vida religiosa en la capital, según las crónicas diarias de El Mundo o el Diario de la Marina, aparecía con frecuencia íntimamente ligada al mundo de la alta sociedad habanera. El "Mundo Católico" del periódico colidiano El Mundo, por ejemplo, aparecía normalmente en el suplemento "Mundo habanero."25 Esto no era una mera coincidencia, especialmente si se recuerda que, para proyectar la imagen de la Iglesia, el cardenal Arteaga se mantenía a la vista del público, inaugurando edificios públicos, con frecuencia acompañando a autoridades del gobiemo, y haciendo visitas de cortesía. ${ }^{26}$ Los lazos entre la alta jerarquía y el gobiemo de Batista se foralecían incluso más allá de lo que podían permitir las actividades caritativas de la esposa del presidente, Martha Femández de Batista, quien, sólo para guardar las apariencias y de forma superficial, hacía donaciones, muy públicas, a la Iglesia. ${ }^{27}$

Hacia fines de los cincuenta, el ser católico era una especie de moda en la alta sociedad, fenómeno que se reflejaba muy elocuentemente en los periódicos. Así, el Diario de la Marina, por ejemplo, siempre ponía el nombre del santo después de la fecha que encabezaba la página. "Domingo de Resurrección," el 6 de abril de 1958, venla seguido de "Santos Celestino, Celso, Urbano y Marcelino." También era frecuente, sobre todo en este mismo periódico, el más antiguo de Cuba, encontrar noticias sociales de la comunidad española -con anuncios referentes al centro gallego, castellano, asturiano, etc. en la misma página de la columna religiosa diaria de Juan Emilio Friguls. Esta yuxtaposición se acentuaba todavia al publicar noticias de sacerdotes que regresaban de veranear en la patria espafiola, y anuncios de las actividades de organizaciones tales como las Hijas de Galicia, la Asociación Canaria o la Asociación Vasco-Navarra de Benefícencia.

Claro está que también había "activistas religiosos" quienes exigian que la caridad fuera acompaftada de la justicia social, pero constituian un número muy reducido, y en general su repercusión en la dirección de la Iglesia católica era muy escasa. Ya hemos mencionado las actividades muy importantes de la Acción Católica, a lo cual hay que antadir las escuelas gratuitas, la campaña "Un techo para el pobre" de los miembros de San Vicente de Paúl, 28 los dispensarios médicos, 29 el servicio de desocupados de la JOC, cuyo lema era: "El mejor regalo para la JOC. ¡Dar trabajo a un joven obrero!,"30 o la fundación, en varias parroquias, de la sociedad Alcohólicos Anónimos. ${ }^{31}$ Todo esto se debe tener en cuenta al hacer un balance del papel de la Iglesia en esa época tan clave para el pueblo cubano.

Al hacer este tipo de análisis hay que recordar que, como en otras partes del mundo católico, en esta época pre-conciliar había pocas personas que pudieran imaginar siquiera cuán importantes serían las consecuencias de los cambios radicales promovidos por Juan XXIII. En Cuba, existía, por una serie de factores ya mencionados, lo que Ernesto Cardenal ha llamado "la Iglesia más reaccionaria en América Latina." 32 Eran poquísimos los católicos preparados para aceptar el aggiornamento del Concilio Vaticano II. Simplemente la Iglesia se preocupaba de predicar una religión espiritualista, apartada claramente de la triste rcalidad en la 
cual vivian la mayoria de los cubanos y, al mismo tiempo, de proteger su recién descubierta respetabilidad. Por ello, no debiera sorprender que en 1955 el directorio oficial de las diócesis de Cuba declarara que "casi toda la emoción de la catolicidad cubana ha girado en este afio alrededor de dos acontecimientos: el centenario de la declaración dogmática del misterio de la Inmaculada Concepción 1854-1954 y las bodas de oro sacerdotales de su Eminencia el Cardenal Arzobispo de la Habana." ${ }^{33}$ Dos aflos más tarde, el padre Chaurrondo, quien, por otra parte, tenía fama de progresista y visitaba con frecuencia a los presos en las cárceles, se concentró en dos novedades eclesiales: el nuevo estilo de edilicios religosos y la "terrible lucha contra la infiltración protestante." 34 Dados los grandes problemas que tenía Cuba en ese momento, la represión de la dictadura, la alta tasa de desempleo, las pobres condiciones de vida sobre todo en el campo, ${ }^{35}$ el hecho de que la Iglesia se preocupara de la fachada de los templos o de la competencia de los protestantes, aparece -mirándolo, claro está, con la gran ventaja de la perspectiva post-conciliar- como un lamentable error estratégico, por decir lo menos.

Entre tanto, e ignorante de las repercusiones del pontificado de Juan XXIU, la Iglesia cubana continuó su marcha en la misma dirección. Seguía teniendo gran éxito el programa de televisión del padre Jaime de Aldeaseca, "Mientras el mundo gira;" se publicaba en la columna del Diario de la Marina la "Guía moral del cine" (en el número del 10 de enero de 1958, a la película Emboscada en la noche se le olorgaba una calificación de "A-1," clasificando a otra película, La reina del strip tease" con la nota más baja, una " $\mathrm{C}$ "); tenían lugar muchas procesiones, como la de antorchas para celebrar el centenario de la aparición de Lourdes; se daban los ejercicios espirituales; se organizaban festivales deportivos "en beneficio misional;" incluso surgió la idea de que "los Pepes y las Josefinas levantaran un templo a su patrón San José;" se organizó una "Cruzada moral en el vestir;"36 abundaban las "Jomadas de penitencia y oración" y las vigilias de la Adoración Noctuma Cubana; se organizaban almuerzos de ex-alumnos del colegio Belén y de otros colegios prestigiosos; y había muchísimas ceremonias para bendecir los ventanales de los templos o los nuevos repartos residenciales. Era simplemente la vida religiosa de una minoría de la población, la cual se movía sólo dentro de su círculo hermético, mientras afuera reinaba la injusticia y la represión.

Salvo algunas excepciones, pues, no existía una verdadera comprensión de la justicia social, ni mucho menos de la necesidad de implantarla en Cuba. Había sí, semanas misioneras, para Cutlack, en India, por ejemplo, pero los dirigentes eclesiásticos parecían estar increíblemente ciegos a la realidad de su propio país. Como indicio anecdótico podemos mencionar la colecta especial que se hizo el 22 de febrero de 1959 en cinco parroquias de la diócesis de Pinar del Río, en otras cuarenta de la arquidiócesis de la Habana y en treinta y ocho iglesias, capillas y colegios, para ayudar a las regiones más dañadas por la reciente guerra civil, en la cual, recordémoslo, murieron unos 20.000 cubanos por derrocar a Batisa. En 
total, después de una campana que recibio bastante publicidad, solo se recogieron 4.903.50 dólares, lo cual evidencia que el cristianismo comprometido no andaba nada bien. Refiriéndose a esta triste situación de la Iglesia, un sacerdote jesuita, en la resefia de un libro reciẹn publicado entonces, indicaba la necesidad de cambiar la superficialidad cristiana:

Imposible reproducir todos y cada uno de los casos expuestos por el Padre Freixedo. En interesante y, para los de arriba, vergonzoso desfile cruzan por las 104 páginas los ejemplos reales, vivos [...] de jóvenes trabajadores, y trabajadores víclimas de un medio social egoísta y farisaico que se autotitula "cristiano," cristianismo que se lleva como una capa que queda en el interior de los templos dominicalmente, o en la bandeja de la colect. ${ }^{37}$

Desgraciadamente para la Iglesia —en vísperas de los cambios radicales que sacudirían a Cuba en 1959, y de los cambios eclesiásticos, que también tendrían un tremendo impacto sobre la Iglesia misma, entre 1962 y 1965 - parecía que nadie escuchaba...

\section{Conclusión}

Al terminar esta aproximación a la Iglesia cubana antes de la revolución y del concilio, se ofrecen dos interpretaciones radicalmente opuestas, cada una de ellas representando los puntos fuertes y los puntos débiles de esta Iglesia. Para los autores de la Reflexión eclesial cubana no cabía duda alguna: "la obra evangelizadora de la Iglesia en Cuba alcanza su período más luminoso y popular en esta etapa de 1899-1959."38 Para ellos hay muchos avances muy importantes que notar. la "cubanización" del clero, el trabajo abnegado de sacerdotes no cubanos, sobre todo de los"españoles con gran amor a Cuba," la religiosidad popular, la organización de la Acción Católica, la construcción de nuevos templos, la respuesta de la Iglesia a "las necesidades primarias de educación, salud, cuidado de niños y ancianos y otras obras sociales," ${ }^{39}$ el surgimiento de las misiones, concentrando su atención en el campo, en fin el "aumento del nivel de catolicismo en Cuba y su compromiso con las aspiraciones y necesidades de nuestro pueblo." 40 Hasta cierto punto no cabe duda de que lienen razón, pues sí se realizaron en ese tiempo grandes proyectos, aunque tal vez no de la extensión indicada por los autores de la Reflexión. Otra perspectiva muy distinta es la que simboliza el gran poeta cubano, Nicolás Guillén, en un poema irónico "A la Virgen de la Caridad," dedicado a la patrona de Cuba:

Virgen de la Caridad, que desde un pefión de cobre

esperanza das al pobre

$y$ al rico seguridad.

En tu criolla bondad, ¡Oh madre!, siempre creí, por eso pido de ti 
que si esa bondad me alcanza

des al rico la esperanza,

la seguridad a mi. ${ }^{41}$

Hasta cierto punto en ambas interpretaciones hay mucho de verdad. Es cierto que la Iglesia realizo grandes progresos sociales y que comenzo a cuestionar la problemática nacional, pero también es verdad que la "línea oficial" seguida por la mayor parte del clero era mantener el status quo, no arriesgar lo que había conseguido en las úlimas décadas -después de muchos altibajos históricos-, y predicar una fe que poco tenía que ver con la realidad cubana.

Es fácil juzgar hoy el comportamiento de esta Iglesia, después de unos 26 afios; pero no hay que olvidar que en el contexto de aquel entonces la realidad era mucho más compleja. Era una época de guardar apariencias, de patemalismo a nivel político y religioso, 42 de dominación económica y cultural por parte de Estados Unidos, de racismo manifiesto, incluso dentro de la iglesia ${ }^{43}$, y de temor a una ruptura radical con el status quo. Hay que reconocer que la Iglesia, influida por una línea pastoral conservadora, fortalecida ésta, a su vez, por la presencia tan fuerte del clero español, y deseosa de proteger sus propios intereses, no estaba preparada en modo alguno para enfrentar los grandes cambios sociales, que entonces se estaban gestando, ni a nivel nacional, ni a nivel eclesial, con las reformas del concilio. A pesar de advertencias y críticas que hacían los mismos intelectuales católicos, ${ }^{44}$ prefirió esconder la cabeza y no hacer caso de la realidad circundante. Si intentamos sintetizar todas estas facelas de la situación de la Iglesia "al borde del volcán," no podemos, tal vez, encontrar una palabra más ariculada ni más precisa que la del arzobispo Pérez Serantes, quien admitió poco antes de su muerte: "todo lo que nos está pasando es providencial [...] conГiamos más en nuestros colegios que en Jesucrisio."45

\section{Notas}

1. Un historiador ha notado que a fines del siglo XVII había unos 700 sacerdoles regulares y seculares, y que en la Habane (con unos 75.518 habicantes) habja unas 33 iglesias , 10 conventos, 8 hospitales, 2 escuelas, una universidad y un seminario. Verse Manual P. Meza, "The Cuban Catholic Church: True Struggles and False Dilemmas," tesis doctoral de la Universidad Georgetown, Washington, D.C., 1982, p. 28.

2. El académico cubano Jorge Tbarta ha indicado que entre 1790 y 1820 fueron imporados aproximadamente unos 227.000 esclavos, y que en 1841 había ya unos 436.500 en Cuba, cifra que representaba el 43.3 por ciento de la población total. Veáse Ibarm, Historia de Cuba, La Habana: Dirección Política de las F. A. R., 1967, p. 129.

3. Reflerión eclesial cubana, Comisión de H'istoria, "Desde la fundación de San Carlos hasta 1902," manuscrilo multicopiado, La Habana, sin fecha, (i1985?) p. 9.

4. Juan Martín Leiseca, Apunses para la historia Eclesidssica de Cuba, La Habana: Talleres Tipográlicos de Carasa y Cla., 1938. p. 159.

5. Reflexión eclesial cubana, "Historia de la Evangelización en Cuba; Parce प: Período de 1899 a 1959," p.l. Adernás, como muestra el "Manifiesto del clero cubano nativo" (suscrito por 52 sacerdotes cubanos), iban surgiendo grandes divisiones entre los religiosos españoles y cubanos: "la misma razón... que ha tenido el pueblo cubeno para haberse levantado en amas, la tiene el clero nativo para no querer depender ya jarnís del clero español; no por soberbia, ni rencores 
indignos de un pecho cristino sino aleccionudos por une doloros experiencil de mis de dos centurias; porque de el clero no hemos recibido mas que vejumenes en castigo del inmenso amor que siempre hemos prolesado a este pedazo de tierre en que nacimos, sucumbiendo los unos, como los Esquembros, bajo el plomo homicida y lanzados los otros al destierro como los Vareins, Santenas, Fuentes, Valdes, Casinfieds, Claras... y unia muchedumbre de sacerdotes cubanos, por el horrendo crimen de haber pensedo con la cabeza y sentido con las entrufins del noble pueblo cubeno. Tal es la razón del reducido o impotente número de clero nativo, por milagro existente, porque se ha querido aniquilamos por todos los medios posibles, parn dominar el clero espartol exclusivamente sobre la conciencia cubana y remachar sus cadenas." Ciudo en ibid., pp. 1-2.

En esu publicación hecha por los invertigadores de la Reflexión eclesial cubana, se destacon las principales dificultades de la Iglesia al teminar la dominacion espariela: alejeda de los mbelos y necesidades del pueblo; empobrecida por las guerros y la escasez de sacerdoces cubanos; acusada de reacia a la independencia; amenazada por otras intitucianes e ideologins; aparición de las denominaciones cristinas no carolicas que en adelanle estarán presentes en el panorama religioso de Cuba (p.9).

6. Es digno de mención el recismo que se practicaba dentro de la sociedad aubana, ya que hasua 1942 no se ordenó el primer sacerdote negro, el padre Armando Arencibia, a quien antes el arzobispo de La Habana, Mons. Manuel Ruiz, se habla negado a ordenar, al parecer porque se crela que no sería "sceplado" por la sociedad cubana, (ibid ., p.22). Mientras el calolicismo "oficial" discriminaba a le población negra, en genend Esta recurría a un sincretismo religioso católico-afrocubano, el cus $x$ practicaber y todevin se practich, con gren frecuencin, sobre todo en el eampo.

7. Un importonte artículo de la revista abana Bohemia desisca con mís detalle el valor de esto contribución. Vesse "Cntolicismo: La Cruz y el Diablo," Bohemia, aĩo 51, No. 3, 18-25 enero, 1959. pp. 98-100.

B. "Exhortamos [...] a todos los que militan en campos antagónicos a que cesen en el uso de la violencia y a que busquen calento antes las soluciones eficaces, que puedan tmer nuevarnente a nuestra patria la paz material y moral que tanta falta le hace. A ese fin no dudarnos que quienes de veras amen a Cuba sabrán acreditarse ante Dios y ante la historia, no negándose a ningún sacrificio para lograr el establecimiento de un gobiemo de unión nacional que pudiera preparar el retomo de nuestra patria a le vida política pacífica y nomal," Ibid., p. 100.

9. Ibid., p. 100.

10. Ibid., p. 100 Véase tambien el segundo capínlo del libro reciente de Pablo M. Allonso, Cuba , Castro y los catolicos, Miami: Ediciones Hispamerican Books, 1985. Pp. 23-41, y Manuel Femández, Religión y revolución en Cubo, Miami: Saeta Ediciones, 1984.

11. El 13 de junio de 1959 , el mismo Fidel Castro trató de suavizar la crítica a la jerarquía católica, sustancialmente porque quería oblener su apoyo para la reforma agraria: "nadie puede poner en duda la actitud de estos dirigentes de la Iglesia católica cuya firme conducta en momentos difíciles es bien conocida. Del gobiemo revolucionario no han recibido ningún favor y no obstante eso se expresan en estos términos en apoyo a una ley tan justa... Con estas declaraciones, la Iglesia cubana se ha colocado en posición verdaderamente revolucionaria; es la Iglesia cabólica más revolucionaria en el orden social." Citado en Alfonso, op. cit., p. S! Un año más tarde, Fidel Castro cambió dramáticamente su opinión.

12. En enero de 1960 se publicó un anículo que analizaba una reunión de los superiores de todas las orderes religiosas en Cuba con el embajador español. Portavoz de la reunión fue el clareliano Arisıónico Ursa quien, enire otras cosas, defendió apasionadamente el gobiemo de Francisco Franco: "ante semejantes evidentes atropellos del gobiemo republicano-marxista, el pueblo español y su cjéreito se alzaron en armas contra la barbaric que asolaba la patria, en una guerra sustancialmente religiosa [...] Esta cruzada es el origen de] actual Esudo español, regido por un hombre inegramente calólico, el Generalisimo Francisco Franco Bahamonde:" véase "Pero Iraen algo más," Bohemia, ario, 52 No. 3. 17 enero, 1960, p. 62. Para tener una ides del número de sacerdotes españoles y su influencia, conviene tener en quenta que eran españoles los superiores de los claretianos, franciscanos, jesuitas, dominicos, capuchinos, salesianos, 
paulinos, cscolapios, maristas, agustinos y redentoristas.

Un ar̉o más tardc, el P. Sardiñas se refirió a este problema, reflejando los sentimientos de muchos sacerdotes cubanos: "es curioso y penoso a la vez que después de 60 años de república, varias provincias cubanas estén gobemadas por españoles. Tenemos al arzobispo de Santiago de Cuba, Monseñor Pérez Serantes; al de Camagüey, Monseñor Carlos Riu, y al de Matanzas que también es español [...] De modo que el clero español es superior en número e importancia, al extremo de que el elemento cubano del sacerdocio se ha sentido cohibido, rebajado y casi coaccionado por esa influencia española un grande." Vése el artículo, "Iglesia: de espaldas al pueblo," Bohemis, afio 53, No. 21, 21 mayo, 1961, p. 61.

13. "El catolicismo social en Cuba abarca, por ora parte, una labor un amplia, y en muchos aspectos desconocida, que obligaría a un trabajo cuya exiensión nos vede los limites de éste: baste deatacar que el caúlogo de obras sociales realizadas por la Iglesia en Cuba abarca 225 instituciones, según el volumen publicado en 1953 por el Secreario Económico Social de la Junta Nacional de Acción Católica Cubana." Entre los ejemplos cilados esún "el Sanatorio 'La Milagrosa' [...], la Escuela Electromecínica de Belén [...], el Hogar 'Sor Peura Vega' del Cerro de los Pp. Salesianos en Guanabacoa; la Escuela Gratuita de los Franciscanos en Miramar y la Parroquia del Cristo." Vtase Hilario Chaurundo, c.m., Almanaque de la caridad: directorio oficial de las diocesis de Cuba (Aĩo de 1958). La Habana: Iglesia de la Merced, 1958, Pp. 9-10.

14. Véase la Reflerión eclesial cubana, "Historia de la Evengelización..." pp. 30-33.

15. Manuel Femández op. cis., p. 15. En su interesante libro cita unas estadisticas del Anuario Pontificio de 1960, indicando que habia 339 colegios católicos, con una matríala de 65.519 alumnos (p.18).

16. "Basts que recorrfis el interiot y vertis cómo en casi todos los pueblecitos existe la iglesia creeda en el periodo anterior." Citado en Alfonso Comln, Cuba, entre el silencio y la utopí, Barcelons: Editorial LAIA, 1979, p. 329.

17. Citado en Maleo Jover Marintan, "The Church," an Carmelo Mesa-Lago, ed., Revolutionary Change in Cuba, Pitrsburgh: University of Pinsburgh Press, 1974, p. 400. Manuel Femindez, orro ex-dirigente cablico, indice como la acoptución del calolicismo dependía del rango social: "Según sus resultodos, el porcentaje de los que se declaraban catolicos entonces, por clases sociales, era del $99 \%$ en la clase alka, el $88 \%$ en la clase media, y el $68 \%$ en los sectores de bajos ingresos," vense Femindez, op. ci., p. 19.

18. Ibid., p. 22

19. Vése Jover Marimón, op. cir., p. 400.

20. Vesse Oscer A. Echaverrie Salvat, La agricultura cubana 1934-1966: régimen social, productividad y nivel de vida del sector agricola, Miemi, Fla: Ediciones Universa, 1971, p. 15 Las cíns pars indicar la asistencia a misa de los campesinos que se declaraban calolicas solo enan un poco mejores: solamente el 4,25\% declart haber ido e misa más de 3 veces al ailo; el $3.49 \%$ de los encuestados asistio 2 veces; el $3.42 \%$, una vez y el $88.84 \%$ de estos urabajadores carblicos admitió no haber ido ninguna vez.

21. Ibid., p. 15

22. Ibid., p. 16

23. Un último ejemplo para mostrar esta lesis. Mientras que el $16.68 \%$ de las parejas entrevistadas se había casado en ceremonia eclesiástica (orro 34.82\% en ceremonin civil, y la mayoria -48.50\%- viví en concubinato) por lo que toea a los "jefes de familia de trabajadores agricolas catolicos," las cifras eran un poco diferentes: $15.99 \%, 38.89 \%$ y $45.12 \%$. respectivamence. Vése /bid., pp. 13 y 17

24. Ibid., p. 24. E 68.73\% opt6 por el gobiemo; 16.72\%, por el patrono; y 6.82\% por el sindicato. Por lodo ello difiero de la opinión de Mnnuel Fernindez, parn quien "no puede decise que la ección pastoral de la Iglesia se redujese a la alu y media burguesía que frecuentaba los colegios catolicos. Le existencia de un clero rural permitio que la Acción Carólica se extendiese a poblacionea remotas, incluso a algunas que careclan de cura estable y hasta de tamplo, haciendo asl el laicado católico cubano una labor pastoral subsidiaria de mucha importancia en las capas sociales más bajas." Véase Femández, op. cir., pp. 15-16. 
25. Vease is edición del 1 de octubre de 1958, por ejemplo. En ese suplemento aparece un artíalo sobre la necesidad del rosario ("Todos los días del año el rosario debe ser nuestro compantero") y el deseo miliente de extender el catolicismo a los infieles. ("Nada mis hermoso en un calólico que pensar en la extensión del reinado de Cristo. Ni tampoco nada a que esté mís obligado"lp. B6).) En el mismo suplemento, sin embargo, hay referencias a varias bodas "del mejor rango social", noticias del "Instituto Cubano de Genealogla y Heraldica" (p. B4), y el aviso de que "una selecta representación femenina colmare hoy los elegantes dominios del exclusivo Country Club de La Habara para participar en el juego de canasta" (p. Bl).

26. Véense los artíalos "Visita el Cerdenal Arteaga al Presidente de la República," Alerta, 3 de mayo, 1952, p. 5, e "Inaguro el generd Batisca la nueva iglesia del Guateo, Diario de la Marisa, 4 rebrero, 1958. pp. 1A y 9B.

27. Vése por ejemplo su papel de "presidente de honor" del comite organizedor de la cuestación pública para apoyar el colegio "Don Bosco" de Guanabocosa, Diario de la Marina, 28 enero, 1958, p. 54, o el artículo de Jusn Emilio Friguls, "Donación de la Primera Dama de la República," Diario de la Marina, 24 abril, 1958, p. 8 a.

28. Vease Friguls, "Audiencia del Cardenal Anega a Vicentinos," Diario de la Marina, 22 mayo, 1958, p. BA.

29. Véase "Dispensario Médico Dentul Católico," Diario de la Marina, 26 mayo, 1958, p. 8A.

30. Velise el anuncio en el Diario de la Marina, 6 de enero, 1959, p. 3A.

31. Vease "Constituida la sociedad de alcohblicos anónimos en Cuba," Diario de la Marina, 9 enero, 1960 , p. 11 A.

32 Emesto Cardentl, In Cuba, New York: New Directions Books, 1974, p. 97.

33. Hilario Chsurrondo, C.M. ed., Almanaque de la Caridad: Direciorio Oficial de las Dibcesis de Cuba (Año de 1955), La Habana: Lglesia de la Merced, 1955, p. 5

34. Hilerio Chaurtondo, C.M., ed., Almanaque de la Caridad: Directorio Oficial de las Dibcesis de Cuba (AMo de 1957), La Habana: lglesin de la Merced. 1957, p. 9.

35. Las propies encuestas de la Agiupación Católica Universitaria habian confirmado los resultados de los censos oficiales: el 43.09\% de jefes de familis en el cempo er analfabeto, y el $44.11 \%$ de ellos jamás habin asistido a la escuela; solamente el $2.12 \%$ comia huevos y el $4.02 \%$ came con frecuencia; y solamente el $6 \%$ de las viviendas tenla suministro de agua corriente. Vése Echevartia Salvat, op. cit., Pp. 18, 19.27, 34.

36. Véase el anuncio en el Diario de la Marina, 25 febrero, 1958, p. 10A. "Aleria, mujer cristiana! Unete fuerienente a la Cruzada de la Moda Moral en el Vesir, Se libre con la moda a us pies. sirviendo a altos ideales. No seas esclova de una moda pagana, que preiende destruir lo $\mathrm{m}$ ís sagrado en la mujer, haciendo de ella un maniqui o una maquinaria. Confiamos en ti."

37. Rodolfo Reisgo, "40 veriades dichas a los ricos," La quinceno atio IV, No. 9, 15 mayo, 1958, p. 15.

38. Reflexión eclesial cubana, "Ręlexión de la Evangelización...," p. 39.

39. Ibid., p. 40.

40. Ibid., p. 40.

41. Nicolśs Guillen, Obra potica 1958-1972, La Habana: Instiuuto Cubuno del Libro, 1973. Tomo II, p. 180.

42. Vése, por ejemplo, el Diario de la Marina del 31 enero, 1958, con le nocicia de que al día siguiente,"cumple cinco artos de edad el gracioso e inteligente niño Fulgencio Jose Batista y Femández Miranda, hijo del Honorable señor presidente de la República, mayor general Fulgencio Batista y Zaldívar, y de su belle y gentilísima esposa Martha Femóndez Mirnan. Con ul motivo y para celebrarto, el pequetio Fulgencito se reunire con los niños de la Casa de Beneficencia en una enorme fiesla en la que habrá una gran piñaca y muchos regalos. También ese día se ofrecerá una rica merienda a los nirios albergados en creches y asilos de loda la República" (p. SA).

43. Se permitíen, por ejemplo, anuncios comerciales como el siguiente: "Solicito mujer blanca, 40 años, cocinar y limpiar casa chica, corta [amilia," publicado en el Diario de la Marina el 9 de marzo de 1958 (p. 13C). Incluso dentro de la Iglesia -como lo muestran el caso del padre 
Arancibia (mencionado antes) y la decisión del cardenal Arteaga (en los aĩos 40)de abrir, finalmente, los seminarios a estudiantes negros- se respelaban esas nomas racirtas.

44. Andrés Valdespino, por ejemplo, poco después del triunfo de las fuerzas fidelistas, conden 6 esta actitud que prevalecla entre la burguesfa calólica: "y cienos 'eristianos' de los que han vivido más apegados al cuidado de sus intereses que al espíritu del evangelio ("No amontonéis tesoros en la tierra," advirió Jesucristo en el sermón de la montaña), no ocultan sus temores ante una revolución que, para ellos, he ido demasiado lejos en su false postura de un cristianismo aburguesado y egolsta, de mucha 'novena' y 'medalla,' y de poca justicia y caridad. El eterno cristianismo farisaico de los sepulctos blanqueados ... esos 'cristianos, cegados por la codicia o preocupados s6lo en acumular riquezas ... esos 'cristianos' de 'crónica social' que cotizan su 'altruismo' a tanto por lisonja y no se acuerdan de los pobres como no sea pregonando ostentosamente su 'espíritu caritativo'... esos 'cristianos' que se dan golpes de pecho en el interior del templo mientras explotan al obrero en su fábrica, arropellan al campesino en sus predios o humillan al criado a su servicio." Véase Andrés Valdespino, "El cristianismo de los sepulcros blanqueados," Bohemio, año S1. No. 11,11 marzo, 1959, p. 64.

Por su parte orro intelectual cabolico, Angel del Cerro, advirió la necesidad de que la Iglesia renovara su interpretación del evangelio: "mientras se siga teniendo la nostalgia de los viejos derechos, mientras se insista en argumentos pasados de moda, mientras se mantengan vinculaciones profundas con grupos sociales o económicos que se han desarrollado medrando en la injusticia y la desigualdad social, mientras su zona de infuencia educacional siga sicndo mayor an las clases ricas que en las clases pobres, mientras no se haga una práctica viva y ejemplar de la prédica de la justicia social católica, mientras esa misma prédica no se realice en el tono y medida que las circuntancias actuales lo demandan, mientras persistan los empecinamientos de las órdenes y las discrepancias de intereses, mientras se mantengan tantos pequeños esfuerzos dispersos de prensa, calequesis y propaganda sin una dirección y coordinación poderosa y eficaz, mientras luche más o menos abiertamente por eualquier privilegio, la Iglesia no estart calificada para la acción que las circunstancias demandan." Véase Angel del Cerro, "La Iglesia tiene que resucitar," Bohemia, año 51, No. 14, 5 abril, 1959, p. 79.

45. Citado en Aldo J. Buinting, "The Church in Cuba: Toward a New Frontier, " Religion in Cuba Today: A New Chroch in a New Society, ed. Alice L. Hageman y Philip E. Wheaton, New York: Association Press, 1971, p. 111. En la Reflexión eclesial cubana, op. cit. se cita la segunda frase solamente ("confiamos más an nuestros colegios y en nuestras instituciones que en Dios," p. 33).

El autor de esta ponencia quisiera agradecer a la Universidad Dalhousic, la Asociación Canadiense para el Estudio de America Latina y el Caribe, y el Social Sciences and Humanities Research Council of Canada, quienes suministraron los fondos para comenzar esta investigación. También quiere agradecer a todas las personas en Cuba quienes lo ayudaron durante el período de investigación aht, en abril de 1984 y en enero de 1985, y sobre todo a Enrique Lopez Oliva, de la Universidad de La Habane; Israel Echeverría, de la Biblioteca Nacional "José Marli;" y al padre Cartos Manuel de Cespedes, secretario general de la conferencis episcopal cubana. Las conclusiones de este proyeca, sin embargo, son responsabilidad del autor. Finaimente quiero agradecer a varios colegas de mi universidad, Antonio Ruiz San Salvador, Bibiana Bunon y Luis Guajardo, quienes me hicieron sugerencias valiosas sobre el manuserito. 